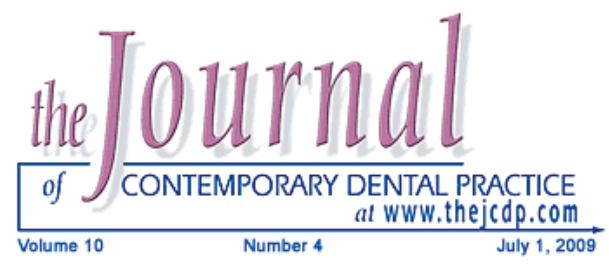

\title{
Bronchial Asthma and Dental Caries Risk: Results from a Case Control Study
}

\author{
Abhishek Mehta, MDS; Peter Simon Sequeira, MDS; \\ Ramesh Chandra Sahoo, MD
}

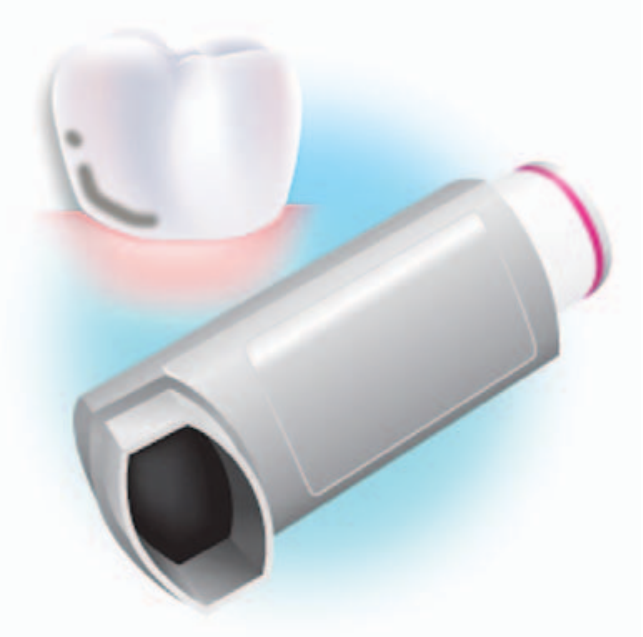

Abstract

Aim: The present study was conducted with the objective of assessing the dental caries status of asthmatic patients in the age group of 11-25 years and to examine the possible association of these conditions to various aspects of bronchial asthma and its management.

Methods and Materials: The present study was conducted on 80 asthmatic patients receiving treatment at the KMC Hospital, Mangalore, India. They were examined for their caries status, and the scores were compared with an age, sex, and socioeconomic status matched group of 80 non-asthmatic patients as controls. The mean age of asthmatics was $17.4( \pm 4.3)$ years and mean duration of asthma was $17.69( \pm 7.66)$ months.

Results: The results showed a significantly higher prevalence of caries among asthmatic patients as compared to the matched control group as well as a positive correlation between the duration of asthma and the caries indices.

Conclusion: There is a need to create awareness among dental practitioners regarding the increased caries risk of asthmatic patients.

Clinical Significance: Special preventive and educational measures will be required to prevent caries and other oral diseases in asthmatic patients.

(c) Seer Publishing 
Keywords: Bronchial asthma, dental caries risk, case control study

Citation: Mehta A, Sequeira PS, Sahoo RM. Bronchial Asthma and Dental Caries Risk: Results from a Case Control Study. J Contemp Dent Pract 2009 July; (10)4:059-066.

\section{Introduction}

Asthma is a serious global health problem. People of all ages in countries throughout the world are affected by this chronic inflammatory airway disorder that can be severe and sometimes fatal. Several oral health conditions are documented among asthmatic patients, especially an increased caries risk.

According to the latest Global Initiative for Asthma (GINA) report, it is estimated as many as 300 million people of all ages and all ethnic backgrounds suffer from asthma. Children, young adults, racial, and ethnic minorities living in urban areas are at the highest risk. ${ }^{1}$

The prevalence of asthma is $3 \%$ of the total population in India with the prevalence among school children being in the range of $4.5 \%$ to as high as $20.3 \% .^{2,3}$ Some of the common risk factors for asthma include the following: ${ }^{4}$

- Female gender

- Advancing age

- Residence in an urban area

- Low socio-economic status

- History suggestive of atopy

- History of asthma in a first degree relative

- All forms of tobacco smoking

Increases in several oral health conditions are associated with asthma such as:

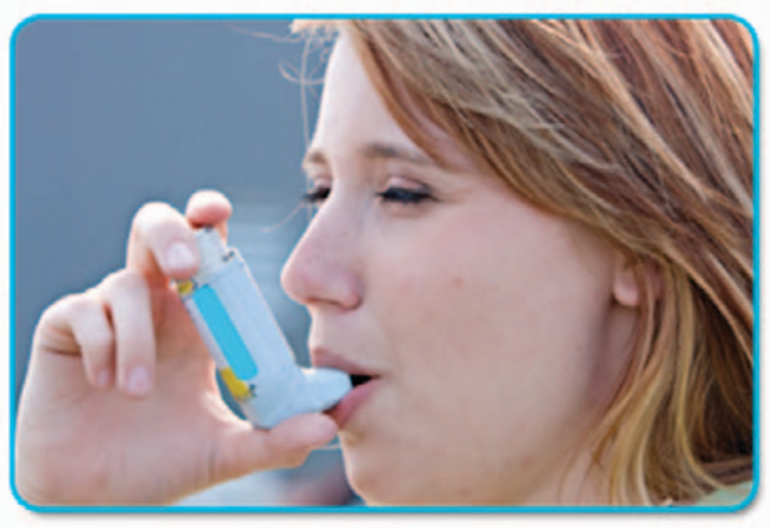

- Rate of caries development and reduced salivary flow.

- Prevalence of oral mucosal changes like oropharyngeal candidiasis.

- Levels of gingivitis and orofacial abnormalities.

Increase in dental caries risk is attributed to prolonged use of $\beta_{2}$-agonists, which is associated with diminished salivary production and secretion. ${ }^{6}$ In addition, inhaler medications used for asthma management reduce salivary flow and plaque $\mathrm{pH}$. They also contain lactose which has shown to be cariogenic during low salivary flow. ${ }^{7}$

Children and young adults are usually at higher risk for dental caries as compared to older age groups due to their lifestyle and dietary habits. Therefore, this risk will be further increased if there is any association between asthma or its medications and caries experience. Various studies $^{7-15}$ have been conducted to determine the prevalence of dental caries in asthmatic patients when compared with a non-asthmatic control group. Results of these studies were conflicting as some studies have shown an increase in caries risk in asthmatic patients, whereas others fail to show any such association. Most of these studies were conducted in Scandinavian countries.

The present study was conducted with the objective to assess the dental caries status of asthmatic patients in the age group of 11-25 years and to examine the possible association of these conditions to various aspects of bronchial asthma and its management.

\section{Methods and Materials}

The present study was conducted with 160 subjects in the age group of 11-25 years, who were divided into two equal groups of asthmatics and controls. The asthmatic group comprised of eighty (80) patients who were suffering from bronchial asthma and receiving treatment at the outpatient section of the Department of Chest Medicine and 
Allergy, KMC Hospital in Attavar, Mangalore, India. Only those patients who were on asthmatic medications (both $\beta_{2}$-agonists and corticosteroids) for at least six months and using an inhaler device for the administration of one type of asthmatic medication were included in the study.

The control group was selected from nonasthmatic school children and individuals who accompanied the study patients to the hospital. They were matched for age, gender, and socioeconomic status with the asthmatic group. The socioeconomic status of the subjects was obtained using Kumar's modification of Prasad's social classification for Indian families, which is a widely used socioeconomic scale in research studies in India. This scale utilizes per capita income of individuals or parents to categorize them into different social classes. ${ }^{5}$ The social class selected for the study consisted primarily of professional workers, traders, and agriculturists of intermediate class with a monthly income in range of $\$ 25-50$ (Social Class-II ${ }^{5}$ ). Both groups consisted of individuals residing within city limits.

A single examiner performed all examinations throughout the study. In accordance with the basic methods of the WHO for conducting oral health surveys intra examiner reproducibility was evaluated by examining a batch of 25 school children at an interval of one week to obtain a caries indices. The Kappa value was found to be more than 0.85 , which shows a high level of agreement. A pilot study was done on 20 asthmatic patients to check for feasibility of the study and to select the particular social class for both groups. Informed consent was obtained from all the individuals before examination.

Examination of subjects was done using a dental chair under standard illumination. Data was collected by means of a proforma designed to collect information regarding a patient's age, gender, and their oral hygiene practices. The DMFT and DMFS Index suggested by Klein et al. ${ }^{6}$ was used to assess the caries experience of the subjects using the following criteria for identification of dental caries:

1. The lesion is clinically visible and obvious.

2. The explorer tip can penetrate deep into soft yielding material.

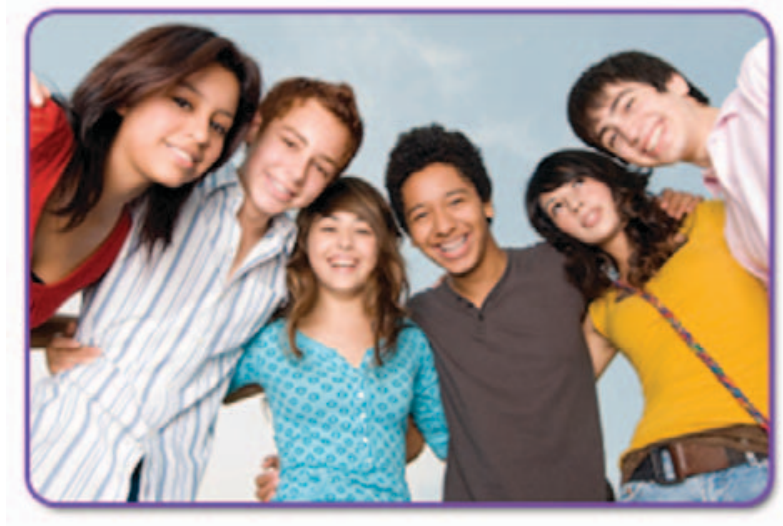

3. There is discoloration or loss of translucency typical of undermined or demineralized enamel.

4. The explorer tip in a pit or fissure catches or resists removal after moderate to firm pressure on insertion and when there is softness at the base of the potentially affected area.

Information regarding the duration and severity of asthma, type of medication prescribed, and the frequency of administration was obtained from medical records of the patients. Asthmatics were categorized into moderate and severe categories according to the National Heart, Lung, and Blood Institute classification system created in the USA in $19977^{7}$

The results were analyzed using the Statistical Package for Social Sciences version 11.0 (SPSS, Inc., Chicago, IL, USA) computer software as follows:

- The Independent Sample t-test was used to compare the indices scores of the study and control groups.

- Analysis of variance (ANOVA) was used to analyze differences in asthmatics in terms of type of medication used and the caries indices score.

- The Pearson Correlation Test was used to determine the correlation between the duration of asthma and caries status.

\section{Results}

The prevalence of dental caries was significantly higher among asthmatics as compared to nonasthmatics. The odds ratio was found to be 3.71 at a $95 \%$ confidence interval. The mean DMFT score was $3.73( \pm 2.03)$ for asthmatic patients and $1.30( \pm 0.97)$ for the non-asthmatic control patients. 
There was a significant difference between the mean DMFT score of the two groups $(p<0.001)$. Table 1 shows the mean DMFS score was 6.38 $( \pm 4.66)$ for asthmatic patients and $2.08( \pm 2.20)$ for the non-asthmatic control patients showing a highly significant difference $(p<0.001)$.

Individuals with a moderate degree of asthma had significantly higher DMFT and DMFS scores as compared to individuals with a severe degree of asthma (Table 2). A possible reason could be due to longer duration of disease among the moderate group as compared to the severe group.

Both groups were further divided into 11-16 yearold and 17-25 year-old groups for comparison between ages. There was a significant higher caries indices score for asthmatics in all age groups, although there was no difference in caries experience within the asthmatic group (Table 3).

Comparison of asthmatics according to sex and type of medication used showed no significant difference in the caries indices scores (Tables 4 and 5).

A positive correlation was seen between the duration of asthma and both the DMFT and the DMFS scores when indices scores were correlated with the duration of asthma. These two correlations were statistically significant at the 0.05 level (Table 6).

\section{Discussion}

The present study is a case-control study conducted on asthmatic patients to assess their

Table 1. Prevalence of dental caries and comparison of DMFT AND DMFS scores in asthmatics and controls.

\begin{tabular}{|l|c|c|c|}
\hline & $\begin{array}{c}\text { Prevalence } \\
(\%)\end{array}$ & Mean DMFT Score & Mean DMFS Score \\
\hline Asthmatics & $73(91.25)$ & 3.73 & 6.38 \\
\hline Controls & $59(73.75)$ & 1.30 & 2.08 \\
\hline $\begin{array}{l}\text { \# Odds ratio }=3.71 \text { at } 95 \% \text { confidence interval } \\
\text { N p value is statistically significant } p<0.001 \\
\text { N p value is statistically significant } p<0.001\end{array}$ \\
\hline
\end{tabular}

Table 2. Comparison of mean DMFT, DMFS scores of asthmatics according to severity of asthma.

\begin{tabular}{|l|c|c|c|}
\hline & Mean & SD & Significance (P) \\
\hline DMFT & 4.45 & 1.88 & \multirow{2}{*}{$0.001^{*}$} \\
\hline Moderate & 3.00 & 1.94 & \\
\hline Severe & 7.65 & 4.72 & \multirow{2}{*}{$0.01^{*}$} \\
\hline DMFS & 5.10 & 4.28 & \\
\hline Moderate & \multicolumn{3}{|l}{} \\
\hline Severe & - P value is statstically significant \\
\hline
\end{tabular}


Table 3. Comparison of mean DMFT, DMFS scores between different age groups

\begin{tabular}{|c|c|c|}
\hline & Mean DMFT* & Mean DMFS** \\
\hline \multicolumn{3}{|l|}{ 11-16 Years } \\
\hline Asthmatics & 2.93 & 4.20 \\
\hline Controls & 0.98 & 1.33 \\
\hline \multicolumn{3}{|l|}{$17-25$ years } \\
\hline Asthmatics & 4.53 & 8.55 \\
\hline Controls & 1.63 & 2.83 \\
\hline
\end{tabular}

Table 4. Comparisons among asthmatics based on sex and mean DMFT, DMFS scores.

\begin{tabular}{|l|l|c|c|c|}
\hline & \multicolumn{1}{|c|}{ Sex } & Mean & SD & Significance (P) \\
\hline \multirow{2}{*}{ DMFT } & Male & 3.42 & 1.95 & \multirow{2}{*}{0.27} \\
\cline { 2 - 4 } & Female & 3.94 & 2.08 & \\
\hline \multirow{2}{*}{ DMFS } & Male & 6.03 & 4.8 & \multirow{2}{*}{0.58} \\
\cline { 2 - 4 } & Female & 6.62 & 4.5 & \\
\hline $\begin{array}{l}\text { Independent sample t-test } \\
\text { P }>0.05 \text { - not significant }\end{array}$
\end{tabular}

Table 5. Comparison of mean DMFT, DMFS scores in asthmatics using different types of inhaler medications.

\begin{tabular}{|l|c|c|c|c|c|}
\hline & $\begin{array}{c}\text { Beclomethsone } \\
\text { dipropionate } \\
\text { (Beclate) }\end{array}$ & $\begin{array}{c}\text { Budesonide } \\
\text { (Budecort, } \\
\text { Deremide) }\end{array}$ & $\begin{array}{c}\text { Fluticasone } \\
\text { propionate and } \\
\text { Salmetrol } \\
\text { (Seroflo) }\end{array}$ & F & $\begin{array}{c}\text { Significance } \\
\text { (P) }\end{array}$ \\
\hline DMFT & $3.67(1.61)$ & $3.53(2.16)$ & $4.26(1.93)$ & 0.888 & 0.416 \\
\hline DMFS & $6.17(3.66)$ & $6.10(4.90)$ & $7.21(4.70)$ & 0.395 & 0.675 \\
\hline $\begin{array}{l}\text { ANOVA test } \\
\text { P>0.05 - not significant }\end{array}$
\end{tabular}


Table 6. Correlation between duration of asthma and DMFT, DMFS scores of asthmatics.

\begin{tabular}{|l|c|c|}
\hline & DMFT & DMFS \\
\hline $\begin{array}{l}\text { Duration of Asthma } \\
\text { (Correlation Coefficient) }\end{array}$ & $0.262^{*}$ & $0.259^{*}$ \\
\hline $\begin{array}{l}\text { Significance } \\
\text { (P) }\end{array}$ & 0.019 & 0.021 \\
\hline $\begin{array}{l}\text {-Pearson Correlation Test } \\
\text { Correlation is significant at the } 0.05 \text { level (2-tailed) }\end{array}$ & & \\
\hline
\end{tabular}

dental caries risk and the possible association of these conditions to various aspects of bronchial asthma and its management. The results were compared with a matched non-asthmatic control group in terms of age, gender, and socioeconomic status.

The difference in mean DMFT score was significant between the two groups which was similar to other studies. ${ }^{7-10}$ However, the findings of the present study differs from some other studies reporting no significant difference between mean DMFT scores of asthmatics and controls. ${ }^{11-14}$

Also, the mean DMFS scores were significantly higher in the asthmatic patients as compared to the controls $(p<0.001)$ for all age groups. McDerra et al. ${ }^{8}$ and Wogelius et al. ${ }^{11}$ reported a similar finding in their studies, while Ryberg et al. ${ }^{10}$ and Bjerkeborn et al. ${ }^{12}$ observed a higher DMFS score in the asthmatic group; the difference was not statistically significant. The decayed component formed a major part of both DMFT and DMFS indices in the present study. This is in agreement with a majority of the studies which showed an increased caries risk in the asthmatic patients.

The possible cause of an increase in caries prevalence among asthmatic patients has been related to the use of $\beta_{2}$-agonists in the treatment of asthma which leads to a reduction in the salivary flow. Ryberg et al. ${ }^{16}$ reported a decrease in the secretion rates of stimulated whole saliva and parotid saliva in asthmatic patients as well as a lower output of salivary components like salivary IgA, lysozyme, amylase, and peroxidase activity compared to non-asthmatic healthy individuals. All these factors play an important role in the antibacterial action of saliva. Laurikainen et al. ${ }^{9}$ observed a statistically significant difference in the mean stimulated salivary flow rate between asthmatic and control groups. A reduced salivary flow is accompanied by a concomitant increase in lactobacilli and streptococcus mutans level in the oral cavity and can increase caries risk in an individual. $^{8}$

Another factor related to an increase in caries risk in asthmatics is the regular use of glucocorticoid medications which have been found to decrease salivary flow and plaque $\mathrm{pH}$ when inhaled. The dry powder inhalers cause a more significant drop in salivary and plaque $\mathrm{pH}$ levels as compared to metered dose inhalers. They also contain lactose monohydrate (so patients can taste the drug being delivered) in the range of $12-25 \mathrm{mg}$ per dose. Although lactose has been shown to be less cariogenic than other sugars, it has cariogenic potential when associated with a reduced salivary flow. ${ }^{17}$

Another factor to consider is the often restricted lifestyles of asthmatic children who miss school and are not able to play sports and participate in other normal childhood activities. Their families may overindulge them with frequent consumption of sweets leading to increased caries levels.

\section{Conclusion}

Based on the findings of this study, asthmatics in the age group studied are at an increased risk for dental caries. 


\section{Clinical Significance}

As asthmatic patients are at risk of dental caries, special preventive and educational measures will be required to prevent caries and other oral diseases in asthmatic patients such as the following:

- Education of the asthmatic patients about their susceptibility to dental caries.
- Regular professional maintenance care and proper home care to prevent dental caries.

- Employment of caries preventive measures like topical fluoride therapy and pit and fissure sealants.

- Treatment of carious lesions at earliest stage to reduce morbidity. 


\section{References}

1. O'Byrne P. Global Strategy for Asthma Management and Prevention; GINA (Global Initiative for Asthma) publication, 2004. Available from: www.ginasthma.com.

2. Pakhale S, Wooldrage K, Manfreda J, Anthonisen N. Prevalence of asthma symptoms in 7th- and 8th-grade school children in a rural region in India. J Asthma 2008 Mar;45(2):117-22.

3. Chhabra SK, Gupta CK, Chhabra P, Rajpal S. Prevalence of bronchial asthma in schoolchildren in Delhi. J Asthma. 1998; 35(3):291-6.

4. Aggarwal AN, Chaudhry K, Chhabra SK, D'Souza GA, Gupta D, Jindal SK, Katiyar SK, Kumar R, Shah B, Vijayan VK. Asthma Epidemiology Study Group. Prevalence and risk factors for bronchial asthma in Indian adults: a multicentre study. Indian J Chest Dis Allied Sci. 2006 JanMar;48(1):13-22.

5. Prasad BG. Changes proposed in the social classification of Indian families. J Indian Med Assoc 1970; 39:198-99.

6. Klein H, Palmer CE, Knutson JW. Studies on dental caries 1. Dental status and dental needs of elementary school children. Publ Hlth Rep. (Washington) 1938; 53:751-765.

7. Steinbacher DM, Glick M. The dental patient with asthma - an update and oral health considerations. JADA 2001; 132:1229-1239.

8. McDerra EJC, Pollard MA, Curzon MEJ. The dental status of asthmatic British school children. Pediatr Dent 1998; 20:281-287.

9. Laurikainen K, Kuusisto P. Comparison of the oral health status and salivary flow rate of asthmatic patients with those of nonasthmatic adults--results of a pilot study. Allergy 1998; 53:316-9.

10. Ryberg M, Moller C, Ericson T. Effect of beta 2 - adrenoceptor agonists on saliva proteins and dental caries in asthmatic children. J Dent Res 1987; 66:1404-1406.

11. Wogelius $P$, Poulsen $S$, Sorensen HT. Use of asthma - drugs and risk of dental caries among 5 to 7 year old Danish children: a cohort study. Community Dent Health 2003; 21:207-11.

12. Bjerkeborn K, Dahllof G, Hedlin G, Lindell M, Modeer T. Effect of disease severity and pharmacotherapy of asthma on oral health in asthmatic children. Scand J Dent Res 1987; 95:15964.

13. Meldrum AM, Thomson WM, Drummond BK, Sears MR. Is asthma a risk factor for dental caries? Findings from a cohort study. Caries Res 2001; 35:235-39.

14. Shulman JD, Taylor SE, Nunn ME. The association between asthma and dental caries in children and adolescents: a population - based case - control study. Caries Res 2001; 35:240-46.

15. Eloot AK, Vanobbergen JN, De Baets F, Martens LC. Oral health and habits in children with asthma related to severity and duration of condition. Eur J Paediatr Dent 2004; 5:210-5.

16. Ryberg M, Moller C, Ericson T. Saliva composition and caries development in asthmatic patients treated with beta 2 - adrenoceptor agonists: a 4-year follow-up study. Scand J Dent Res 1991; 99:212-8.

17. Ginty J. Asthma medication and caries. Br Dent J 1997; 182:88.

\section{About the Authors}

\section{Abhishek Mehta, MDS}

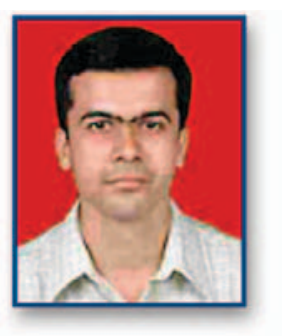

Dr. Mehta is an Assistant Professor in the Department of Public Health Dentistry of the Swami Devi Dyal Dental College in Panchkula, Haryana, India.

e-mail: mehta_abhishek2003@yahoo.co.in 
Peter Simon Sequeira, MDS

Dr. Sequeira is a Professor and Head of the Department of Public Health Dentistry at the Coorg Institute of Dental Sciences in Coorg, Karnataka, India.

Ramesh Chandra Sahoo, MD

Dr. Sahoo is a Professor and Head of the Department of Chest Medicine and Allergy at the KMC Hospital in Attavar, Mangalore, India. 